\title{
Software Requirements Specification
}

Verifiable Fuel Cycle Simulation (VISION) Model

AFCl Economic Benefits and Systems Analysis Team

January 2005 
INEEL/EXT-05-02643, Rev. 0

\title{
Software Requirements Specification Verifiable Fuel Cycle Simulation (VISION) Model
}

\author{
AFCl Economic Benefits and Systems Analysis Team
}

January 2005

Idaho National Engineering and Environmental Laboratory Idaho Falls, Idaho 83415

Prepared for the

U.S. Department of Energy

Office of Nuclear Energy, Science, and Technology

Under DOE Idaho Operations Office

Contract DE-AC07-99ID13727 


\section{ACKNOWLEDGMENTS}

The AFCI Economic Benefits and Systems Analysis Team acknowledges the efforts of those who contributed to this document: D. E. Shropshire, INEEL; K. A. Williams, ORNL; W. B. Boore, WSRC; J. D. Smith, SNL ; B. W. Dixon, INEEL; M. DunzikGougar, INEEL; R. D. Adams, INEEL; J. J. Jacobson, INEEL; W. H. West, INEEL; Steve Piet, INEEL; Gretchen Matthern, INEEL; Robert Hill, ANL; Latif Yacout, ANL; Erich Schneider, LANL. 


\section{Table of Contents}

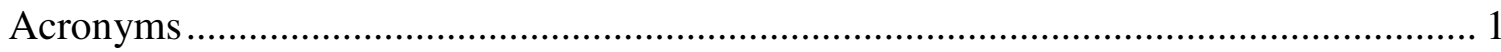

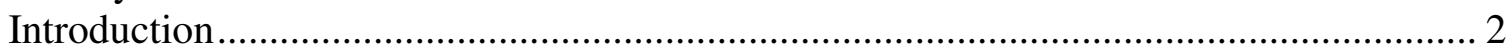



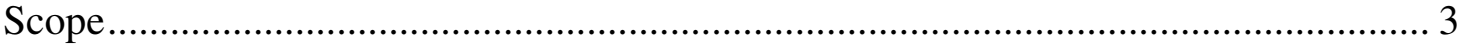

System Definition and Top-Level Module Features......................................... 3





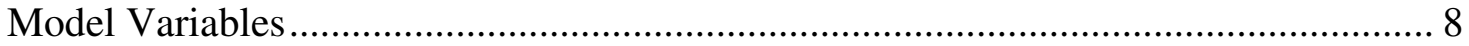

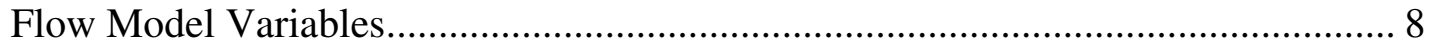

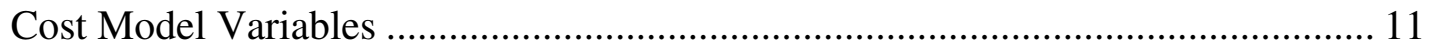

Analysis of Estimates or Measures ........................................................................ 13

General Model Architecture Elements.................................................................. 15

Hardware/Software ........................................................................................ 22

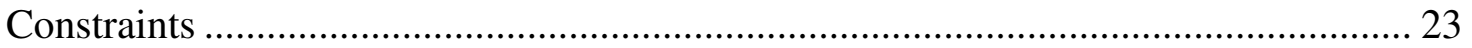

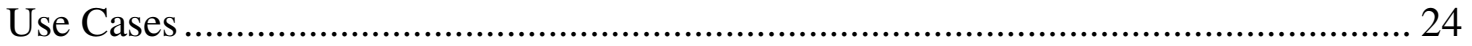

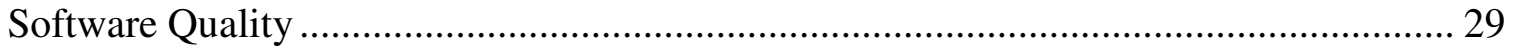

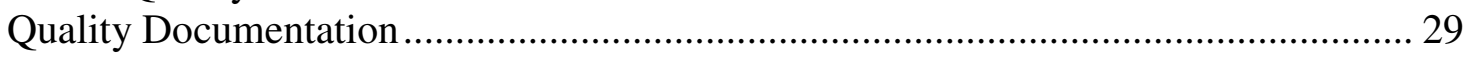

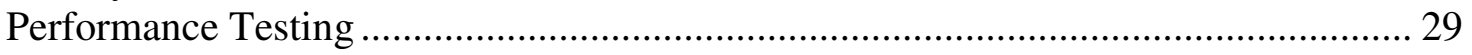

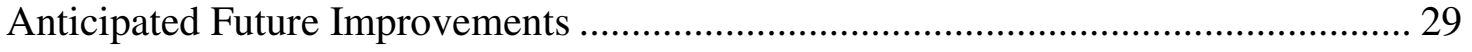

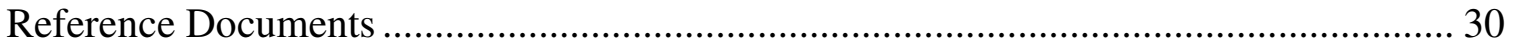




\section{Acronyms}

AFC

AFCI

BCC

$\mathrm{CH}$

COA

D\&D

DDS

DOE

EMWG

FICA

FOAK

HLW

IAEA

IDC

INEEL

LFR

LLW

LUEC

MRS

MSR

NOAK

NRC

O \& M

OCRWM

R\&D

RD\&D

$\mathrm{RH}$

RTM

SCMP

SCWR

SFR

SMP

SNF

SQAP

SRS

SRS

STP

SWU

TCIC

TOC

TSLCC

$\mathrm{V} \& \mathrm{~V}$

VHTR

VISION

WBS

WIT

WU
Advanced Fuel Cycle

Advanced Fuel Cycle Initiative

Base Construction Cost

Contact Handled

Code of Accounts

Decontamination and Decommissioning

Design description for software

U.S. Department of Energy

Economic Modeling Working Group

Federal Insurance Contribution Act

First-of-a-Kind

High-level Waste

International Atomic Energy Agency

Interest During Construction

Idaho National Engineering and Environmental Laboratory

Lead-Cooled Fast Reactor

Low-level Waste

Levelized Unit of Electricity Cost

Monitored Retrievable Storage

Molten Salt Reactor

Nth-Of-A-Kind

Nuclear Regulatory Commission

Operations and Maintenance

Office of Civilian Radioactive Waste Management

Research and Development

Research, Development, and Demonstration

Remote Handled

Requirements traceability matrix

Software configuration management plan

Supercritical-Water-Cooled Reactor

Sodium-Cooled-Fast Reactor

Software management plan

Spent Nuclear Fuel

Software quality assurance plan

Software requirements specification

Software Requirements Specification

Software test plan

Separative Work Unit

Total Capital Investment Cost

Total Overnight Cost

Total System Life Cycle Cost

Verification and Validation

Very-High Temperature Reactor

Verifiable Fuel Cycle Simulation Model

Work Breakdown Structure

What-It-Takes

Weapons Useable 


\section{Introduction}

The purpose of this Software Requirements Specification (SRS) is to define the top-level requirements for a Verifiable Fuel Cycle Simulation Model (VISION) of the Advanced Fuel Cycle (AFC). This simulation model is intended to serve as a broad systems analysis and study tool applicable to work conducted as part of the AFCI (including costs estimates) and Generation IV reactor development studies. This is a "living document" that will be modified over the course of the execution of this work element.

This SRS describes the requirements for a simulation model supporting the AFCI Program. The goal of the model is to establish a credible systems basis for AFC and to create a reference source for fuel cycle unit costs. The model will simulate distinct fuel cycle activities, called modules, which represent the various front-end fuel cycle, backend fuel cycle, waste disposition, and transportation functions.

Verification and validation refers to the process of determining whether the requirements for a system or component are complete and correct, the products of each development phase fulfill the requirements or conditions imposed by the previous phase, and the final system or component complies with specified requirements. Validation evaluates the system or component to determine if it satisfies specified requirements. Verification evaluates the system or component for proof of correctness.

There is a lack of verified estimating models to support fuel cycle cost analysis. Previous cost studies have failed to provide a complete economic accounting of all the relevant fuel cycle costs (e.g., omission of D\&D costs, refurbishment, or waste forms) that comprise the overall life cycle costs of a facility. Such "partial" studies can result in misleading conclusions.

\section{Objective}

The objective of VISION is to evaluate the elements of the fuel cycle that discriminate the different advanced fuel cycles. Specifically:

- Perform dynamic scoping trade studies of alternative fuel cycles to obtain qualitative and quantitative comparisons of resource requirements, reactor types and mix, sequencing and timing, waste streams, and repository requirements, with capability to provide cost estimates of levelized cost of electricity and cash flow/funding requirements.

- Model the nuclear fuel cycle such that dynamic changes in process capability, including transition from "design and construct to startup to equilibrium to final D\&D" states as well as material, capital, and operating costs, can be factored into a Levelized Life Cycle Cost or other benefit comparison.

- Quickly assess relative economic differences in fuel cycle strategies and timing with reasonable accuracy.

- Provide economic estimates consistent with the YMP economic analysis so the numbers can be compared.

- Provide a range of model outputs that can support both technical and management review. 
- Interact (in some fashion) with higher-level models, e.g., that compare among energy source options.

- Interact (in some fashion) with lower-level models, e.g., those providing detailed cost and process estimations for individual facilities.

- Provide parameters that are critical to comparing AFCI options, including repository capacity and performance, interim waste storage, energy recovery, proliferation resistance, and safety.

\section{Scope}

The VISION is intended to serve as a broad systems analysis and study tool applicable to AFC (including costs estimates) and Generation IV reactor development studies. The model will simulate the AFC from cradle to grave, including mining of raw material to disposition of waste after electricity generation.

\section{System Definition and Top-Level Module Features}

Each type of fuel cycle facility or activity is referred to as a module (see Figure 1). A module represents a specific fuel cycle function that is separate but dependent on other fuel cycle activities (e.g., the enrichment module is influenced by the enrichment required by the fuel manufactured in the fuel fabrication module). The modules are assembled in various ways to create different fuel cycle scenarios. 




Figure 1. AFC Model Modules 


\section{Front-end Modules}

The front-end fuel cycle modules (A, B, C, D1) are generally related to commodity types of services provided by commercial sources. The costs for these types of operations are often market driven and may be provided by many sources both domestically and internationally. These modules will not use facility code of accounts (COA) breakdown information, but are based on market related unit costs (e.g., U.S. $\$ / \mathrm{Kg} \mathrm{UF}_{6}$ ). Information for Module D, fuel fabrication, is available from a limited number of sources and some detailed cost data is available at a facility level.

\begin{tabular}{|c|c|c|}
\hline $\mathrm{A}$ & $\begin{array}{l}\text { Natural Uranium } \\
\text { Mining and Milling }\end{array}$ & $\begin{array}{l}\text { Includes the factors involving extraction of uranium } \\
\text { from the earth through production of uranium } \\
\text { concentrate in the form of } \mathrm{U}_{3} \mathrm{O}_{8} \text { commonly known as } \\
\text { "yellowcake." } \\
\text { This module will include modeling of stockpiled } \\
\text { military material, depleted uranium and Th/Th-U ore. }\end{array}$ \\
\hline B & Conversion & $\begin{array}{l}\text { Takes the mined } \mathrm{U}_{3} \mathrm{O}_{8} \text { concentrate and further purifies } \\
\text { and converted to a } \mathrm{UF}_{6} \text { solid in cylinders for feed to a } \\
\text { uranium enrichment plant. }\end{array}$ \\
\hline $\mathrm{C}$ & $\begin{array}{l}\text { Enrichment } \\
\text { (Isotopic Separation) }\end{array}$ & $\begin{array}{l}\text { Uses the } \mathrm{UF}_{6} \text { solid in cylinders to enrich the } \% \text { of } \mathrm{U} \text { - } \\
235 \text { from } 0.711 \% \text { to the } 3-5 \% \text { typical of the enrichment } \\
\text { used for fuel fabrication. }\end{array}$ \\
\hline D1 & $\begin{array}{l}\text { Fuel Fabrication - } \\
\text { Unirradiated } \\
\text { (contact handled) }\end{array}$ & $\begin{array}{l}\text { Uses chemical, ceramic/metallurgical, and mechanical } \\
\text { steps to take enriched } \mathrm{UF}_{6} \text { and convert it to finished } \\
\text { fuel assemblies. }\end{array}$ \\
\hline
\end{tabular}

\section{Reactor Modules}

Reactors are integral to the fuel cycle. Reactor/transmutation baseline cost data is provided in Appendix C of the 2004 Advanced Fuel Cycle Cost Basis.

\begin{tabular}{|l|l|l|}
\hline R1 & Thermal & $\begin{array}{l}\text { The module will differentiate LWR vs. VHTR, } \\
\text { current reactor (with limitations on MOX and IMF } \\
\text { percentage of core) vs. new LWR, on-line versus } \\
\text { batch refueling, on-site vs. centralized } \\
\text { reprocessing, and conversion ratio. }\end{array}$ \\
\hline R2 & Fast & $\begin{array}{l}\text { The module will differentiate on-line vs. batch } \\
\text { refueling, on-site vs. centralized reprocessing, and } \\
\text { conversion ratio. }\end{array}$ \\
\hline
\end{tabular}

\section{SNF Storage Modules}

The SNF storage (Module E) and SNF packaging for transport and disposal (module H) are generally located at reactor sites. Their costs are based on commercial cost data associated with the reactor construction and operation. The reactor operator may have added dry storage pads some time after reactor construction. 


\begin{tabular}{|l|l|l|}
\hline E1 & $\begin{array}{l}\text { Interim SNF storage }- \\
\text { reactor wet }\end{array}$ & $\begin{array}{l}\text { Pool storage of SNF from existing commercial reactor } \\
\text { operations. }\end{array}$ \\
\hline E2 & $\begin{array}{l}\text { Interim SNF storage }- \\
\text { reactor dry }\end{array}$ & $\begin{array}{l}\text { Dry storage of SNF coming from reactor wet storage } \\
\text { and includes handling costs involved with transfer from } \\
\text { wet to dry storage. }\end{array}$ \\
\hline
\end{tabular}

\section{Recycling Modules}

The recycle modules (D2, E3, F, G, J, K and P) associated with reprocessing of the fuel and may be provided by some combination of government and private sources. Cost data is generally derived from international and domestic sources with various ownership arrangements.

\begin{tabular}{|c|c|c|}
\hline D2 & $\begin{array}{l}\text { Fuel Fabrication - } \\
\text { recycled } \\
\text { (remote handled) }\end{array}$ & $\begin{array}{l}\text { Uses chemical, ceramic/metallurgical, and mechanical } \\
\text { steps to take fissile material from the back-end fuel } \\
\text { cycle to convert to finished fuel assemblies. } \\
\text { This module will include modeling the use of } \\
\text { commercial nuclear power plants and fuel fabrication } \\
\text { facilities to draw down the inventory of weapons grade } \\
\text { material (either highly enriched Uranium or Pu). }\end{array}$ \\
\hline E3 & $\begin{array}{l}\text { Recycled } \\
\text { product/Decay storage }\end{array}$ & $\begin{array}{l}\text { Storage of the U and TRU products produced from the } \\
\text { reprocessing of thermal reactor and fast reactor fuels. } \\
\text { Would typically be required to support blending needs. } \\
\text { Recycled fuel products indefinite storage - Storage of } \\
\text { TRU components (e.g. Cm in some scenarios) for } \\
\text { purposes of decay. Because these components have } \\
\text { some fuel value, their consideration in economics is } \\
\text { different than non-fuel components, and they may } \\
\text { indeed be used in later reactor types. } \\
\text { Recycled non-fuel components storage - Storage of } \\
\text { non-fuel components (e.g. Cs, Sr) for purposes of } \\
\text { decay. }\end{array}$ \\
\hline $\mathrm{F} 1$ & $\begin{array}{l}\text { Reprocessing - } \\
\text { Aqueous } \\
\text { (Elemental Separation) }\end{array}$ & $\begin{array}{l}\text { Separation of SNF elemental components using } \\
\text { aqueous process to support recycling of fissile } \\
\text { materials. Includes cost of receipt of SNF through end- } \\
\text { product production. }\end{array}$ \\
\hline $\mathrm{F} 2$ & $\begin{array}{l}\text { Reprocessing - } \\
\text { Pyrolytic } \\
\text { (Elemental Separation) }\end{array}$ & $\begin{array}{l}\text { Separation of SNF elemental components using a } \\
\text { pyrolytic process to support recycling of fissile } \\
\text { materials. Includes cost of receipt of SNF through end- } \\
\text { product production. }\end{array}$ \\
\hline G & $\begin{array}{l}\text { HLW Conditioning, } \\
\text { Storage, and Packaging }\end{array}$ & $\begin{array}{l}\text { Conditions the waste, provides interim storage of the } \\
\text { treated waste, and packages the HLW in preparation for } \\
\text { transport to a repository. }\end{array}$ \\
\hline $\mathrm{J}$ & $\begin{array}{l}\text { Near Surface Disposal } \\
\text { (LLW) }\end{array}$ & $\begin{array}{l}\text { Engineered or trench disposal of LLW including waste } \\
\text { and fill placement, and monitoring. }\end{array}$ \\
\hline
\end{tabular}




\begin{tabular}{|l|l|l|}
\hline $\mathrm{K}$ & $\begin{array}{l}\text { Depleted Uranium } \\
\text { Disposition/storage }\end{array}$ & Conversion and disposal of depleted $\mathrm{UF}_{6}$. \\
\hline $\mathrm{P}$ & $\begin{array}{l}\text { LLW }(\mathrm{CH} \text { and } \mathrm{RH}) \\
\text { Transportation }\end{array}$ & $\begin{array}{l}\text { Transportation cost of LLW per relative unit, includes } \\
\text { handling costs not already included in interim storage } \\
\text { costs. }\end{array}$ \\
\hline
\end{tabular}

\section{Back-end Modules}

Some of the back-end fuel cycle modules (I, L and M) are the responsibility of the government as provided by the Nuclear Waste Policy (NWPA) ${ }^{1}$. Only a limited number of these types of facilities would be built.

\begin{tabular}{|l|l|l|}
\hline $\mathrm{H}$ & $\begin{array}{l}\text { SNF Packaging for } \\
\text { Transport and Disposal }\end{array}$ & $\begin{array}{l}\text { Includes cost of required operations to condition and } \\
\text { package the SNF for shipment to the repository, interim } \\
\text { storage, or to a reprocessing facility. }\end{array}$ \\
\hline I & $\begin{array}{l}\text { Long-Term Monitored } \\
\text { Retrievable Storage } \\
\text { (MRS) }\end{array}$ & $\begin{array}{l}\text { Long-term storage of SNF/HLW until shipped to a } \\
\text { geologic repository. }\end{array}$ \\
\hline $\mathrm{L}$ & Geologic Repository & $\begin{array}{l}\text { Includes cost from inception through closure for } \\
\text { repository operations. Based upon OCRWM data and } \\
\text { projected cost estimates. }\end{array}$ \\
\hline $\mathrm{M}$ & $\begin{array}{l}\text { Other Disposal } \\
\text { Concepts }\end{array}$ & $\begin{array}{l}\text { Speculative costs for SNF/HLW disposal alternatives to } \\
\text { a deep geologic repository, such as deep bore hole, and } \\
\text { others. }\end{array}$ \\
\hline
\end{tabular}

\section{Transportation Modules}

The transportation modules are associated with transportation of material (raw material, fuel, waste, etc.) and may be provided by some combination of government and private sources. Transportation is a component of almost every aspect of the AFC and can contribute significant costs to any scenario.

\begin{tabular}{|l|l|l|}
\hline $\mathrm{N}$ & $\begin{array}{l}\text { Nuclear fuel } \\
\text { transportation } \\
\text { (CH \& RH) }\end{array}$ & $\begin{array}{l}\text { Transportation cost for new fuel, unirradiated materials, } \\
\text { and recycled irradiated fuel per relative cost unit. } \\
\text { Fresh fuel - Fresh, unirridated. } \\
\text { Recycled fuel - Recycled fuel (irridated) - I'm sure the } \\
\text { cost of this will be significantly different than fresh } \\
\text { fuel. }\end{array}$ \\
\hline O & $\begin{array}{l}\text { SNF/HLW } \\
\text { Transportation }\end{array}$ & $\begin{array}{l}\text { Transportation cost of SNF/HLW per relative unit, } \\
\text { includes handling costs not already included in interim } \\
\text { storage costs. }\end{array}$ \\
\hline Q1 & $\begin{array}{l}\text { Transport of mined or } \\
\text { milled Uranium }\end{array}$ & \\
\hline
\end{tabular}

\footnotetext{
${ }^{1}$ Information on the NWPA can be found at http://www.ocrwm.doe.gov/ymp/about/nwpa.shtml.
} 


\begin{tabular}{|c|c|c|}
\hline $\mathrm{Q} 2$ & $\begin{array}{l}\text { Transport of Converted } \\
\text { Raw material }\end{array}$ & \\
\hline Q3 & $\begin{array}{l}\text { Transport of Depleted } \\
\text { Uranium }\end{array}$ & \\
\hline Q4 & $\begin{array}{l}\text { Transport of Enriched } \\
\text { material }\end{array}$ & \\
\hline Q5 & Transport of SNF & $\begin{array}{l}\text { Among reactor, centralized storage (if any), } \\
\text { reprocessing (if any) }\end{array}$ \\
\hline Q6 & Transport of HLW & $\begin{array}{l}\text { Among reprocessing, interim storage, geologic disposal } \\
\text { sites }\end{array}$ \\
\hline
\end{tabular}

\section{Assumptions}

Existing models that satisfy all or part of the expectations and requirements described in this document will be located and be used if possible.

Some new development or modification of existing models will be needed to satisfy all the requirements.

The model needs to be developed or modified in time to help provide cost estimates for decisions anticipated in 2007.

The model will be distributed and used beyond the INEEL.

The model will be of sufficient quality to pass independent external (external to the INEEL) review for compliance with requirements and for technical soundness.

\section{Expectations or Requirements}

The following section describes the team's/customer's expectations for VISION. These expectations are divided into six major subject areas and two sub-subject areas. Some of the expectations are further identified as "requirements" for the model. The requirements designation indicates the model must satisfy these expectations. Non-requirement expectations are considered important but not essential or critical to model success. The model would still be used even if expectations are not satisfied.

\section{Model Variables}

The following list represents those estimates or measures VISION should do to satisfy the AFCI Economics Benefits and Systems Analysis team requirements. These estimates or measures are broken down into two major areas: Flow Model Variables and Cost Model Variables.

\section{Flow Model Variables}

In the tables below, the priority metrics has two categories: Relative importance and implementation stage. The importance metric has three ranges: required, desirable and 
optional. The implementation stage is split into three ranges: FY05, FY06 and beyond FY06.

Importance rating
Required
Desirable
Optional

Implementation Stage

FY05 (summer)

FY06 (next years plan) beyond FY06

\subsection{Track Mass Inventories}

Description:

At the end of each time step, track mass $(\mathrm{Kg})$ inventories of Fuel, SNF, Recycled material, HLW, LLW, TRU by:

1. Model module

2. Inventory at each generation of recycle

3. Location scenario selected by the user (see requirement 4.13).

Priority:

Required/FY05

Acceptance Criteria: User selectable table(s)/chart(s) that tracks the estimated mass flows and inventories of Fuel, SNF, Recycled material, HLW, LLW and TRU. (Modules affected: All Modules)

Revision Date $\quad 01 / 31 / 2005$

Revision Number: $\quad 0$

1.2 Track Elements/Isotopes Mass Inventories Description:

At the end of each time step for each module implemented after the reactor modules, track the mass $(\mathrm{Kg})$ inventories and process losses of the elements/isotopes: $\mathrm{Pu}, \mathrm{Pu}-238$, $\mathrm{Pu}-239, \mathrm{Pu}-240, \mathrm{Pu}-241, \mathrm{Pu}-242, \mathrm{Am}, \mathrm{Am}-241, \mathrm{Am}-242 \mathrm{~m}$, Am-243, Cm, Cm-244, Cs, Cs-135, Cs-237, Sr, Sr-90, Th, Th-232, U, U-233, U-235, U-236, U-238, Np, Np-237, Tc, Tc-99, Zr, Zr-93, I, I-129, and C-14 for each:

1. Model module

2. Inventory at each generation of recycle

3. Location scenario selected by the user (see requirement 4.13).

Priority:

Required/FY05 for most isotopes (Pu isotopes, Am isotopes, $\mathrm{Np}$ isotopes, Cs isotopes, $\mathrm{Sr}$ isotopes, $\mathrm{Tc}$ isotopes, I isotopes)

Acceptance Criteria: User selectable table(s)/chart(s) that tracks the mass flows, inventories, and process losses of the elements/isotopes for each module downstream of the reactor modules. (Modules affected: All modules except A, B, C, D1, K) Decay of Pu-241, Cm-244, Sr-90, and Cs-137 must be accounted for as change during the simulation period and especially during fuel storage time periods.

Revision Date $01 / 31 / 2005$

Revision Number:

0 


\subsection{SNF composition Description:}

Priority:

Acceptance Criteria:

Revision Date

Revision Number:
For a given reactor or transmutation model estimate how much (Kg) of : $\mathrm{Pu}, \mathrm{Pu}-238, \mathrm{Pu}-239, \mathrm{Pu}-240, \mathrm{Pu}-241, \mathrm{Pu}-$ 242, Am, Am-241, Am-242m, Am-243, Cm, Cm-244, Cs, Cs-135, Cs-237, Sr, Sr-90, Th, Th-232, U, U-233, U-235, U-236, U-238, Np, Np-237, Tc, Tc-99, Zr, Zr-93, I, I-129, and $\mathrm{C}-14$ contained in SNF composition.

Required/FY05 for most isotopes ( $\mathrm{Pu}$ isotopes, Am isotopes, $\mathrm{Np}$ isotopes, $\mathrm{Cs}$ isotopes, $\mathrm{Sr}$ isotopes, $\mathrm{Tc}$ isotopes, I isotopes)

Required/FY06 for other isotopes

User selectable table(s)/chart(s) that track the listed estimated elements/isotopes contained in SNF composition. (Modules affected: E1, E2, F1, F2, H, O, I, L) $01 / 31 / 2005$

0
1.4 U Needed

Description:

Priority:

Acceptance Criteria:

Revision Date

Revision Number:
Estimate the mass $(\mathrm{Kg})$ of fissile composition (i.e. U, U233, U-235, U-236, U-238) needed.

\section{Required/FY05}

User selectable table(s)/chart(s) that tracks the estimated mass of $U$ needed based on input parameters and outcome results. (Modules affected: D1)

$01 / 31 / 2005$

0
1.5 Material Availability

Description:

Priority:

Acceptance Criteria:

Revision Date

Revision Number:
Estimate material availability, timing, and volume of recycle materials.

\section{Required/FY05}

User selectable table(s)/chart(s) that track estimated raw material available. (Modules affected: A, B, C, D1, K) $01 / 31 / 2005$

0

1.6 Transportation Volume Description:

At the end of each time step, estimate the kg-miles transported per year between scenario locations (see requirement 4.13) for:

1. Uranium concentrates,

2. Fabricated fuel,

3. SNF,

4. Recycled fuel,

5. Waste

Priority: Desirable/FY06 or FY07 
Acceptance Criteria: User selectable table(s)/chart(s) that tracks transported material. (Modules affected: $\mathrm{N}, \mathrm{O}$ )

Revision Date $\quad 01 / 31 / 2005$

Revision Number: $\quad 0$

1.7 Number Of Shipments

Description:

At the end of each time step, estimate the number of shipments based on the transportation type(s) selected to a repository for:

1. SNF,

2. HLW,

Priority:

Desirable/FY06 or FY07

Acceptance Criteria: User selectable table/chart that tracks estimated number of shipments, based on transportation type(s) selected to a repository.( Modules affected: $\mathrm{N}, \mathrm{O}$ )

Revision Date 01/31/2005

Revision Number: $\quad 0$

\subsection{Energy Efficiency Factor}

Description: Calculate changes in energy efficiency factor.

Priority: Required/FY05

Acceptance Criteria: User selectable table/chart that tracks estimated energy

efficiency factor.

Revision Date 01/31/2005

Revision Number: $\quad 0$

\subsection{Radiotoxicity Index Of SNF/HLW}

Description:

Calculate the radiotoxicity index, integrated long-term heat, groundwater dose index, neutron emission rate, gamma field and weapons usable (WU) inventory of SNF/HLW.

Priority: $\quad$ Required/FY05 for radiotoxicity and WU inventory Required/FY06 for everything else

Acceptance Criteria: User selectable table/chart that tracks radiotoxicity index of SNF and waste based on input scenario. (Modules affected:

E1, D2, H, F1, F2, J, M, I, L, O)

Revision Date $\quad 01 / 31 / 2005$

Revision Number: $\quad 0$

\section{Cost Model Variables}

2.1 Ownership Cost

Description:
At the end of the model run, estimate the total cost (\$) of facility ownership to:

1. government,

2. private

3. and hybrid (government and private). 
Recognize that different facilities have different "owner" ship.

Priority: Desirable/FY06

Acceptance Criteria: User selectable table(s)/chart(s) that display the estimated cost of ownership for the each facility type and ownership type.

Revision Date $\quad 01 / 31 / 2005$

Revision Number: $\quad 0$

2.2 Life-Cycle Cost Description:

Priority: Acceptance Criteria:

Revision Date Revision Number:
Estimate the Life-Cycle Cost (\$) of a scenario. Including cost data from reference report Desirable/FY06

User selectable table(s)/chart(s) that displays the estimated Life-Cycle Cost (\$) (All Modules) $01 / 31 / 2005$

0

2.3 Levelized Unit of Electricity Cost

Description:

Estimate LUEC ( $\$ / \mathrm{kWh})$ component of the cost of electricity (see requirement 4.7).

Priority: Desirable/FY06

Acceptance Criteria: User selectable table(s)/chart(s) that displays the estimated LUEC ( $\$ / \mathrm{kWh}$ ) (All Modules)

Revision Date $01 / 31 / 2005$

Revision Number:

0

2.4 Separation Cost Description:

Estimate the separation cost as a function of different separation combinations ( $\$ / \mathrm{kg}-\mathrm{MTiHM})$.

Priority: Desirable/Beyond FY06

Acceptance Criteria: User selectable table/chart that tracks separation cost as a function of separation combinations. (F1, F2)

Revision Date $01 / 31 / 2005$

Revision Number:

0

2.5 Fuel Fabrication Cost Description:

Estimate recycle fuel fabrication cost $(\$ / \mathrm{kg})$ as function of:

1. fuel type,

2. gamma field,

3. neutron emission rate,

4. heat rate

5. and facility size.

Priority: Desirable/Beyond FY06

Acceptance Criteria: User selectable table/chart that tracks recycle fuel fabrication cost as a function of above areas. (D1, D2)

Revision Date $01 / 31 / 2005$ 
Revision Number: $\quad 0$

2.6 Concentrated U Cost

Description:

Estimate 3 separate components of concentrated U cost (\$/kg-U) for:

(a) Mining and milling

(b) Conversion

(c) Enrichment (SWU)

Priority: Desirable/FY06

Acceptance Criteria: User selectable table/chart that tracks estimated

concentration $\mathrm{U}$ cost as a function of Modules A, B, and C

Revision Date 01/31/2005

Revision Number: $\quad 0$

2.7 HLW Disposal Cost

Description:

Estimate HLW disposal cost $(\$ / \mathrm{kg})$ as function of disposed mass, volume, and form.

Priority: Desirable/FY06

Acceptance Criteria: User selectable table/chart that tracks estimated HLW

disposal cost as a function of disposed mass, volume, and form. (Modules affected: O, I, M, L)

Revision Date $\quad 01 / 31 / 2005$

Revision Number: $\quad 0$

\section{Analysis of Estimates or Measures}

3.1 Alternative Comparison

Description:

Display alternative strategies/scenarios in an easy to compare format such as chart and/or table with differences calculated for all model variables.

Priority: Required/FY05

Acceptance Criteria: Charts and tables that list multiple scenario results to allow easy comparison of scenario outcomes. (User interface)

Revision Date 01/31/2005

Revision Number: $\quad 0$

\subsection{Sensitivity}

Description:

Perform sensitivity analysis of outcome values based on selected/key input parameters. Display the results in a chart and/or table.

Priority: Desirable/Beyond FY06

Acceptance Criteria: Sensitivity analysis functionality.

Revision Date 01/31/2005

Revision Number: $\quad 0$

3.3 Optimize A Scenario

Description:
Optimize selected output variables based on a set of selected 
Priority: $\quad$ Desirable/Beyond FY06

Acceptance Criteria: Optimization functionality with user defined objective functions.

Revision Date 01/31/2005

Revision Number: $\quad 0$

3.4 Reactor Construction

Description:
Calculate when reactors are constructed (fleet size) based on unsatisfied electricity/H2/other demand, retirement age of existing reactors, first available date for new design, mix for $\mathrm{U}$ and TRU management, economics (such as mill/kW-hr if a function of burnup, amount to be sent to repository, $\mathrm{CO} 2$ credits, government economic factors, anywhere in the system, etc.). Consider both $\mathrm{H} 2$ and electricity OR link with other models e.g. NERAC

Priority: $\quad$ Required/FY05

Acceptance Criteria: Reactor fleet size determined dynamically based on above criteria.

Revision Date 01/31/2005

Revision Number: $\quad 0$
3.5 Reactor Number And Mix Description:

Priority:

Acceptance Criteria:

Revision Date

Revision Number:

0
Calculate the reactor number and mix based on total unsatisfied electric and/or H2/other demand, retirement age of existing reactors, first available date for new design, mix for $\mathrm{U}$ and TRU management, economics (such as mill/kW$\mathrm{hr}$ if a function of burnup, amount to be sent to repository, $\mathrm{CO} 2$ credits, government economic factors, anywhere in the system, etc.). Consider both $\mathrm{H} 2$ and electricity OR - link with other models e.g. NERAC Required/FY05

Reactor number and mix determined dynamically based on electric demand.

$01 / 31 / 2005$

\subsection{Reprocessing Capacity}

Description:

The model should dynamically create reprocessing capacity based on need, unit size, and time to construct (forward projection).

Priority: Required FY05

Acceptance Criteria: Reprocessing capacity is determined dynamically based on need, unit size, and time to construct.

Revision Date $01 / 31 / 2005$

Revision Number: 


\section{General Model Architecture Elements}

4.1 Graphical User Interface

Description:

Develop a Graphical User Interface (GUI) for selection of values of input variables and user-selected options.

Priority: Required/FY06 or Beyond

Acceptance Criteria:

Revision Date

A usable GUI to run the scenarios.

Revision Number:

$01 / 31 / 2005$

0

4.2 Default Values

Description:

Provide default values for all input variables.

Priority:

Required/FY05

Acceptance Criteria:

Input parameters are initialized with default values at the start of the simulation.

Revision Date

$01 / 31 / 2005$

Revision Number:

0

4.3 Multi-dimensional Arrays

Description:

Provide the capability to work with a two-dimensional array expanding to multi-dimensional arrays in later years

Priority:

2 dimensions $=$ Required $/ \mathrm{FY} 05$

$>2$ dimensions $=$ Required/FY06

Acceptance Criteria:

Revision Date 01/31/2005

Revision Number: $\quad 0$

4.4 Input interface

Description:

Model could be run:

(a) only through GUI,

(b) input deck,

(c) at the programming/modeling level

Priority:

(a) only through GUI, - Required/FY06 or Beyond

(b) input deck, - Optional/FY06 or Beyond

(c) at the programming/modeling level - Required/FY05

Acceptance Criteria: Selectable interface based on technical expertise or password profile

Revision Date 01/31/2005

Revision Number: $\quad 0$

4.5 Select Inappropriate Input Warnings

Description:

Allow user to select the level of warning for inappropriate input. Model can be run with

(a) prevent inappropriate input values,

(b) allow but warn,

(c) warning turned off. 
Priority:

Acceptance Criteria:

Revision Date

Revision Number:
If running in GUI mode, automatically prevent inappropriate input values. If running in "input deck" or "programming/modeling" level, then prevent, warn, nowarn are all options.

\section{Optional/Beyond FY06}

Limited input ranges on input parameters.

$01 / 31 / 2005$

0
4.6 Reactor Mixes

Description:

Priority:

Acceptance Criteria:

Revision Date

Revision Number:
Allow the user to define the mix of reactors and adjust the mix through time.

Required/FY05

Interface that allows the user to specify the reactor mix. $01 / 31 / 2005$

0
4.7 Reactor Cost

Description:

Priority:

Acceptance Criteria:

Revision Date

Revision Number:
Allow the user to input reactor cost or set the cost to zero for fuel cost estimates only. Desirable/FY06

Interface that allows the user to specify reactor cost. $01 / 31 / 2005$

0

4.8 Fuel "Types" and burn-up

Description:

Allow the user to define fuel "types" in terms of reactor type, achievable burn up, etc.

Priority: Required/FY05

Acceptance Criteria: Interface that allows the user to specify fuel types in terms of reactor type, achievable burn up.

Revision Date $01 / 31 / 2005$

Revision Number:

0

4.9 Burn Up Rates

Description:

Priority:

Acceptance Criteria:

Revision Date

Revision Number:
Select among discrete values associated with discrete input/discharge data composition sets, each labeled as to its burn up.

\section{Required/FY05}

Interface that allows the user to select discrete burn up rates based on reactor/fuel types.

$01 / 31 / 2005$

0

4.10 Reprocessing Throughput Description:

Allow users to adjust input to reprocessing facility as 
function of fuel age (minimum). Allow as strategies

(a) youngest fuel first,

(b) oldest fuel first.

In either case, also allow user to determine/input minimum fuel age at time of reprocessing. (default value is 5 years)

Priority: $\quad$ Oldest fuel first: Required/FY05

Youngest fuel first: Required/FY06

Acceptance Criteria: Interface that allows the user to adjust reprocessing throughput as a function of fuel age.

Revision Date $\quad 01 / 31 / 2005$

Revision Number: $\quad 0$

4.11 The Size/Throughput Rates

Description:

Allow the user to adjust the size/throughput rates of specific classes of facilities (modules) for scaling of costs.

Priority: Desirable/FY06

Acceptance Criteria: Interface that allows the user to adjust the size/throughput rates for scaling costs.

Revision Date $\quad 01 / 31 / 2005$

Revision Number: $\quad 0$

4.12 Modes of Operation Description:
Priority:

Acceptance Criteria:

Revision Date

Revision Number:
ALLOW three modes of model operation:

(a) User input controls discrete processing plant capacity growth + discrete repository capacity growth. Then interim storage is the free variable and both processing plant and repository unit sizes must be input/default.

(b)User input controls discrete processing plant and interim storage capacity limit. Then repository inventory is the free variable.

(c) User input controls interim storage and discrete repository. Then processing plant required is the free variable.
(a) $=$ Required/FY05
(b) and (c) are Required/FY06

Interface that allows the user to select the fixed variables between processing plant capacity, repository capacity and interim storage capacity and then dynamically adjust the necessary level for the third variable.

$01 / 31 / 2005$

0

\subsection{Location Scenarios}

Description:
Allow the user to select different location scenarios (e.g. onsite processing, regional, national, or fixed (e.g. 1500 miles)). 
Priority: Desirable/FY06

Acceptance Criteria: Interface that allows the user to select different location scenarios (on-site, national, regional, or fixed).

Revision Date 01/31/2005

Revision Number: $\quad 0$

4.14 Modes Of Transportation

Description: $\quad$ Allow the user to select different modes of transportation for each material stream and the volume per load for a specific transportation mode.

Priority: Desirable/FY06

Acceptance Criteria: Interface that allows the user to select different transportation modes and volumes for material streams.

Revision Date $\quad 01 / 31 / 2005$

Revision Number: $\quad 0$

4.15 Energy Outlook

Description: Allow user to either:

(a) define growth rate,

(b) use default projection such as EIA,

(c) input data from other models,

(d) dynamic link with other models

Priority: $\quad$ (a) $=$ Required/FY05

(b) and (c) $=$ Desirable/FY06

(d) = Optional/Beyond FY06

Acceptance Criteria: Interface that allows the user to specify the energy demand from either a user defined growth rate or from a variety of internal and external sources.

Revision Date $\quad 01 / 31 / 2005$

Revision Number: $\quad 0$

4.16 Timing And Sequencing

Description:

Allow the user to define the timing and sequencing both within and between for some modules.

Priority: Required/FY05

Acceptance Criteria: Interface that allows the user to adjust the timing and sequencing both within and between modules.

Revision Date $\quad 01 / 31 / 2005$

Revision Number: $\quad 0$

4.17 Select Input Materials Streams

Description:

Allow the user to select for different input materials streams (e.g. fuel).

Priority: $\quad$ Required/FY05 for fundamental fuel types

Acceptance Criteria: Interface that allows the user to specify different input material streams.

Revision Date $\quad 01 / 31 / 2005$ 
Revision Number: $\quad 0$

\subsection{Select For Recycled Streams}

Description:

Priority:

Acceptance Criteria:

Revision Date

Revision Number:
Allow the user to select different recycled product streams coming out of recycling. Required/FY05 for fundamental options (IMF, MOX, etc.) Interface that allows the user to specify different recycled product streams coming out of recycling. $01 / 31 / 2005$

\subsection{Loading And Fuel Management Scheme}

Description:

Acceptance Criteria:

Revision Date

Revision Number:
Allow the user to input the loading and fuel management scheme (how much of each fuel type to start up, how much core/target/blanket replaced each refueling, etc.) for each reactor type.

Required/FY05 for at least some crude model Interface that allows the user to input loading and fuel management schemes (how much of each fuel type to start up, how much core/target/blanket replaced each refueling, etc) for each reactor type.

$01 / 31 / 2005$

0
4.20 Escalation Schemes Description:

Priority:

Acceptance Criteria:

Revision Date

Revision Number:
Allow the user to input different escalation schemes (e.g., use U.S. Department of Labor statistics for escalation of operations costs.).

Desirable/FY06

Interface that allows the user to specify which escalation scheme to use (e.g., US Department of Labor statistics for escalation of operations costs).

$01 / 31 / 2005$

0

\subsection{Interest Rate}

Description:

Allow the user to input different interest rates (e.g., use U.S. Department of Treasury statistics for interest rates). Selectable as different for different capital projects (at the module level) in fuel cycle, esp. if owner varies.

Priority: Desirable/FY06

Acceptance Criteria: Interface that allows the user to specify which escalation scheme to use (e.g., US Department of Labor statistics for escalation of interest rates).

Revision Date $01 / 31 / 2005$

Revision Number: $\quad 0$ 
4.22 Objective Function Description:

Priority:

Acceptance Criteria:

Revision Date

Revision Number:
Allow the user to define an objective function that will optimize a specific set of outcome parameters based on selected model parameters. (see optimization requirement 3.3).

Optional/Beyond FY06

User definable objective function for optimization.

01/31/2005

0

\subsection{Save Input Files}

Description:

Allow the user to save input files to a file name and location of their choice and to reuse the saved file for later runs. Or create input files from other sources outside of this model.

Priority: Required/FY05

Acceptance Criteria:

Revision Date

Menu item to select and store scenario input data.

Revision Number:

$01 / 31 / 2005$

0

\subsection{Graphical Output}

Description:

Have the ability to produce graphical output of all model variables or reports/variables from an available list (see requirement 4.25 ) as they change through time.

Priority:

\section{Required/FY05}

Automatic for users with program/modeling access.

Pre-designed graphics $=$ Required/FY06

Acceptance Criteria: Functionality to produce charts/tables of all model variables selected by the user.

Revision Date 01/31/2005

Revision Number: $\quad 0$

4.25 Select Outputs

Description:

Allow the user to select the number and type of output display or charts from an available list.

Priority:

\section{Required/FY05}

Acceptance Criteria: Interface that allows the user to specify the type of output (charts/tables) for each system variable.

Revision Date $01 / 31 / 2005$

Revision Number:

\subsection{Flag Extreme Conditions}

Description:

Priority:

Flag output variables that exceed reasonable conditions.

Acceptance Criteria:

Revision Date

Revision Number:

\section{Desirable/Beyond FY06}

Extreme condition warning messages that flag when the model has exceeded reasonable conditions.

$01 / 31 / 2005$

$$
0
$$




\subsection{Drill Down Capability}

Description:

Provide high-level summary outputs that users can "drill down" through to increasing levels of detail. (Casual tracing is a powerful tool to analyze system behavior.)

Priority: Required/FY06

Acceptance Criteria: Layered summary reports that allow progressively more detailed sub-reports.

Revision Date 01/31/2005

Revision Number: $\quad 0$

\subsection{Time Step Capability}

Description:

Provide high-level summary outputs that users can step through time to interpret system behavior.

Priority: Required/FY06

Acceptance Criteria: Interface that allows the user to step through time and view the selected outputs.

Revision Date 01/31/2005

Revision Number: $\quad 0$

\subsection{Save Output Files}

Description:

Priority:

Allow the user to save output files to a file name and location of their choice.

Acceptance Criteria: Menu item to select and store scenario output data.

Revision Date $01 / 31 / 2005$

Revision Number:

0

\subsection{Internal Consistency Checks}

Description:

Priority:

Acceptance Criteria:

Revision Date

Revision Number:
Provide model internal consistency checks to prevent running simulation cases that are not physically realizable. Desirable/FY06

Functionality to prevent unrealistic conditions. $01 / 31 / 2005$

0

4.31 Non-Linear Changes In Cost Variable

Description:

Priority:

Acceptance Criteria:

Revision Date

Revision Number:
Provide for non-linear changes in cost variable such as materials supply. Desirable/FY06

Functionality to use non-linear functions in cost variables. $01 / 31 / 2005$

0
4.32 Fuel Blending Description:
Provide for ability to accommodate fuel-blending requirements relative to supply and product constraint 
Priority: Desirable/Beyond FY06

Acceptance Criteria: Functionality to blend fuel based on supply and product constraints.

Revision Date $\quad 01 / 31 / 2005$

Revision Number: $\quad 0$

\section{Hardware/Software}

\subsection{Computer}

Description:

The model should run on a standalone desktop PC or laptop computer using current technology and a MS Windows operating system.

Priority: $\quad$ Required/FY05

Acceptance Criteria: Runs on desktop systems/laptops using Windows operating systems

Revision Date 01/31/2005

Revision Number: $\quad 0$

\subsection{Software}

Description:

The model should be developed using off-the shelf commercial software.

Priority: Required/FY05

Acceptance Criteria:

Developed using commercial software.

Revision Date 01/31/2005

Revision Number:

0

5.3 Transparent Architecture

Description: The model should have a transparent architecture (Ability to view model language source code and detailed documentation on equations, assumptions etc.).

Priority: $\quad$ Required/Start in FY06 Finish in FY07

Acceptance Criteria: User can view model and model equations.

Revision Date 01/31/2005

Revision Number: $\quad 0$

5.4 Non-Proprietary

Description:

Priority:

Acceptance Criteria:

Revision Date

Revision Number:
The model should be non-proprietary.

\section{Required/FY05}

No proprietary requirements. $01 / 31 / 2005$

0

\subsection{Distribution}

Description:

Priority:
The model should be distributed at a minimal charge to users.

Desirable/Beyond FY06 
Acceptance Criteria: Less than $\$ 10$ charge for distribution.

Revision Date 01/31/2005

Revision Number: $\quad 0$

\section{Constraints}

6.1 Constraints from Advanced Fuel Cycle Cost Basis

Description: The model's default and uncertainty ranges should use all assumptions and formulas (e.g. code of accounts, U.S.

Dollar as the monetary standard, base year for all calculations, etc.) as defined in the 2004 Advanced Fuel Cycle Cost Basis Document. Model constraints will be updated as the Advanced Fuel Cycle Cost Basis Document is updated.

Priority: $\quad$ Required/FY06

Acceptance Criteria: Verify that defaults and uncertainty ranges match.

Revision Date 01/31/2005

Revision Number: $\quad 0$

6.2 Cost Data

Description:

Use selected cost data (e.g. the sunk, operations and buildup costs of repository) developed by RW.

Priority: Required/FY06

Acceptance Criteria: Ability to select RW's Cost data.

Revision Date 01/31/2005

Revision Number: $\quad 0$

\subsection{YMP Consistency}

Description:

Present output units consistent with the YMP economic

Priority: analysis so the numbers can be compared.

Acceptance Criteria: Output units are consistent with YMP economic analysis.

Revision Date

Required/FY06

Revision Number:

$01 / 31 / 2005$

0

6.4 Time Step

Description:

Priority:

Acceptance Criteria:

Revision Date

Revision Number:
Have a minimum time unit of one month and a maximum time unit of one year.

Required/FY05

Time step with a minimum of one month and a maximum of one year.

$01 / 31 / 2005$

0
6.5 Stochastic

Description:

Priority:
Provide for stochastic inputs for selected variables. Required/FY06 
Acceptance Criteria: Functionality should exist to allow the model to use stochastic inputs for selected variables.

Revision Date 01/31/2005

Revision Number: $\quad 0$

\section{Use Cases}

The following use cases were identified as the minimum set of scenarios the model must be able to simulate. The model is not limited to these cases and the user will be able to develop other cases by selecting the input parameters appropriate their area and level of interest.

\subsection{Case 1}

Description:

Strategy $=\quad$ Once through

Development Phases $^{2}=0$

Energy future $(3$ cases $)=$

- Continuing energy generation ( $0 \%$ growth, market share $21 \%$ to $9 \%$ in 2050 and $4 \%$ in 2100 )

- Continuing nuclear market share (1.8\% growth, $21 \%$ constant market share)

- Growing Market Share Generation (3.2\% growth, market share of electricity increases, $\mathrm{H} 2$ produced)

Exit approaches $=$

At all times, estimate the ramifications of separations phase-out, i.e., a return to once-through.

Separation $=\quad$ None

Transmutation $=$ LWR

$\mathrm{U}=\quad \mathrm{SNF}$

$\mathrm{Pu}=\quad \mathrm{SNF}$

$\mathrm{Np}=\quad \mathrm{SNF}$

$\mathrm{Am}=\quad \mathrm{SNF}$

$\mathrm{Cm}=\quad \mathrm{SNF}$

$\mathrm{Cs}+\mathrm{Sr}=\quad \mathrm{SNF}$

$\mathrm{Tc}+\mathrm{I}=\quad \mathrm{SNF}$

Priority: Required/FY06

Lanthanides $=\mathrm{SNF}$

Acceptance Criteria: Able to run Case 1 use case.

Revision Date 01/31/2005

Revision Number: $\quad 0$

7.2 Case 2

Description:

Strategy $=\quad$ Thermal Recycle

Development Phases $=\quad 1.5$

Energy future $(3$ cases $)=$

\footnotetext{
${ }^{2}$ As defined in the AFCI development plan.
} 
- Continuing energy generation ( $0 \%$ growth, market share $21 \%$ to $9 \%$ in 2050 and $4 \%$ in 2100)

- Continuing nuclear market share (1.8\% growth, $21 \%$ constant market share)

- Growing Market Share Generation (3.2\% growth, market share of electricity increases, $\mathrm{H} 2$ produced)

Exit approaches $=$

At all times, estimate the ramifications of separations phase-out, i.e., a return to once-through.

Separation $=$ UREX +

Transmutation $=$ LWR

$\mathrm{U}=\quad$ Retrievable LLW

$\mathrm{Pu}=\quad \mathrm{IMF}$ (1-pass) then direct to HLW

$\mathrm{Np}=\quad$ IMF (1-pass) then direct to HLW

$\mathrm{Am}=\quad \mathrm{IMF}$ (1-pass) then direct to HLW

$\mathrm{Cm}=\quad \mathrm{IMF}$ (1-pass) then direct to HLW

$\mathrm{Cs}+\mathrm{Sr}=\quad$ Long-term storage, then LLW

$\mathrm{Tc}+\mathrm{I}=\quad$ HLW

Priority:

Lanthanides $=\mathrm{HLW}$

Acceptance Criteria: Able to run Case 2 use case.

Revision Date 01/31/2005

Revision Number: $\quad 0$

7.3 Case 3

Description:
Strategy $=\quad$ Thermal Recycle

Development Phases $=\quad$ 2-->3-->4

Energy future $(3$ cases $)=$

- Continuing energy generation ( $0 \%$ growth, market share $21 \%$ to $9 \%$ in 2050 and $4 \%$ in 2100)

- Continuing nuclear market share (1.8\% growth, $21 \%$ constant market share)

- Growing Market Share Generation (3.2\% growth, market share of electricity increases, $\mathrm{H} 2$ produced)

Exit approaches $=$

At all times, estimate the ramifications of

separations phase-out, i.e., a return to once-through.

Separation $=\quad$ UREX +

Transmutation $=$ LWR

$\mathrm{U}=\quad$ Retrievable LLW

$\mathrm{Pu}=\quad \mathrm{Pu}+\mathrm{Np}+\mathrm{Am}$ MOX (N-pass)

$\mathrm{Np}=\quad \mathrm{Pu}+\mathrm{Np}+\mathrm{Am} \mathrm{MOX}(\mathrm{N}$-pass $)$

$\mathrm{Am}=\quad \mathrm{Pu}+\mathrm{Np}+\mathrm{Am}$ MOX (N-pass)

$\mathrm{Cm}=\quad$ Storage

$\mathrm{Cs}+\mathrm{Sr}=\quad$ Long-term storage, then LLW

$\mathrm{Tc}+\mathrm{I}=\quad$ HLW

Lanthanides $=$ HLW 
Priority: $\quad$ Required/FY06

Acceptance Criteria: Able to run Case 3 use case.

Revision Date 01/31/2005

Revision Number: $\quad 0$

\subsection{Case 4}

Description:

Strategy $=\quad$ Thermal+Fast Recycle

Development Phases $=\quad 2-->3-->4$

Energy future $(3$ cases $)=$

- Continuing energy generation ( $0 \%$ growth, market share $21 \%$ to $9 \%$ in 2050 and $4 \%$ in 2100 )

- Continuing nuclear market share (1.8\% growth, $21 \%$ constant market share)

- Growing Market Share Generation (3.2\% growth, market share of electricity increases, $\mathrm{H} 2$ produced)

Exit approaches $=$

At all times, estimate the ramifications of separations phase-out, i.e., a return to once-through.

Separation $=\quad$ UREX + , then pyro

Transmutation $=$ LWR, then "FR"

$\mathrm{U}=$

Retrievable storage, then "FR"

$\mathrm{Pu}=\quad \mathrm{Pu}+\mathrm{Np} \mathrm{IMF}$

$\mathrm{Np}=\quad \mathrm{Pu}+\mathrm{Np} \mathrm{IMF}$

$\mathrm{Am}=\quad$ Storage, then "FR"

$\mathrm{Cm}=\quad$ Storage, then "FR"

$\mathrm{Cs}+\mathrm{Sr}=\quad$ Long-term storage, then LLW

$\mathrm{Tc}+\mathrm{I}=\quad \mathrm{HLW}$

Priority: $\quad$ Required/FY06

Lanthanides $=$ HLW

Acceptance Criteria: Able to run Case 4 use case.

Revision Date 01/31/2005

Revision Number: 0

\subsection{Case 5}

Description:

Strategy $=\quad$ Thermal+Fast Recycle

Development Phases $=$ 2-->3-->4

Energy future $(3$ cases $)=$

- Continuing energy generation $(0 \%$ growth, market share $21 \%$ to $9 \%$ in 2050 and $4 \%$ in 2100)

- Continuing nuclear market share (1.8\% growth, $21 \%$ constant market share)

- Growing Market Share Generation (3.2\% growth, market share of electricity increases, $\mathrm{H} 2$ produced)

Exit approaches $=$

At all times, estimate the ramifications of

separations phase-out, i.e., a return to once-through.

Separation $=\quad$ UREX + , then pyro 
Priority:

Acceptance Criteria:

Revision Date

Revision Number:

$\begin{array}{ll}\text { Transmutation= } & \text { LWR, then "FR" } \\ \mathrm{U}= & \text { Retrievable storage, then "FR" } \\ \mathrm{Pu}= & \text { Pu+Np MOX } \\ \mathrm{Np}= & \text { Pu+Np MOX } \\ \mathrm{Am}= & \text { Storage, then "FR" } \\ \mathrm{Cm}= & \text { Storage, then "FR" } \\ \mathrm{Cs}+\mathrm{Sr}= & \text { Long-term storage, then LLW } \\ \mathrm{Tc}+\mathrm{I}= & \text { HLW } \\ \text { Lanthanides }= & \text { HLW } \\ \text { Required/FY06 } & \\ \text { Able to run Case } & 5 \text { use case. } \\ 01 / 31 / 2005 & \\ 0 & \end{array}$

Transmutation= LWR, then "FR"

$\mathrm{U}=$

Retrievable storage, then "FR"

$\mathrm{Pu}=$ $\mathrm{Pu}+\mathrm{Np}$ MOX

$\mathrm{Am}=$ Storage, then "FR"

$\mathrm{Cm}=$ Storage, then "FR"

$\mathrm{Cs}+\mathrm{Sr}=$ Long-term storage, then LLW

$\mathrm{Tc}+\mathrm{I}=$ HLW

Lanthanides $=$

Able to run Case 5 use case.

0

\subsection{Case 6}

Description:
Priority:

Acceptance Criteria:

Revision Date

Revision Number:
Strategy $=\quad$ Fast Recycle

Development Phases $=\quad 3-->4$

Energy future $(3$ cases $)=$

- Continuing energy generation (0\% growth, market share $21 \%$ to $9 \%$ in 2050 and $4 \%$ in 2100)

- Continuing nuclear market share (1.8\% growth, $21 \%$ constant market share)

- Growing Market Share Generation (3.2\% growth, market share of electricity increases, $\mathrm{H} 2$ produced)

Exit approaches $=$

At all times, estimate the ramifications of separations phase-out, i.e., a return to once-through.

Separation $=\quad$ Pyro

Transmutation= "FR"

$\mathrm{U}=$

Retrievable storage, then "FR"

$\mathrm{Pu}=\quad$ FR recycle of all 4 TRU

$\mathrm{Np}=\quad$ FR recycle of all 4 TRU

$\mathrm{Am}=\quad$ FR recycle of all $4 \mathrm{TRU}$

$\mathrm{Cm}=\quad$ FR recycle of all $4 \mathrm{TRU}$

$\mathrm{Cs}+\mathrm{Sr}=\quad$ Long-term storage, then LLW

$\mathrm{Tc}+\mathrm{I}=\quad$ HLW

Lanthanides $=$ HLW

Required/FY06

Able to run Case 6 use case.

01/31/2005

0

\subsection{Case 7}

Description:

Strategy=

Thermal Recycle

Development Phases $=$ 1.5

Energy future $(3$ cases $)=$ 
share $21 \%$ to $9 \%$ in 2050 and $4 \%$ in 2100 )

- Continuing nuclear market share (1.8\% growth, $21 \%$ constant market share)

- Growing Market Share Generation (3.2\% growth, market share of electricity increases, $\mathrm{H} 2$ produced)

Exit approaches $=$

At all times, estimate the ramifications of

separations phase-out, i.e., a return to once-through.

Separation $=\quad$ UREX+

Transmutation $=$ LWR with some VHTR

$\mathrm{U}=\quad$ Retrievable LLW

$\mathrm{Pu}=\quad \mathrm{IMF}$ (1-pass) then direct to HLW

$\mathrm{Np}=\quad$ IMF (1-pass) then direct to HLW

$\mathrm{Am}=\quad \mathrm{IMF}$ (1-pass) then direct to HLW

$\mathrm{Cm}=\quad$ IMF (1-pass) then direct to HLW

$\mathrm{Cs}+\mathrm{Sr}=\quad$ Long-term storage, then LLW

$\mathrm{Tc}+\mathrm{I}=\quad$ HLW

Lanthanides $=$ HLW

Priority: Required/FY06

Acceptance Criteria: $\quad$ Able to run Case 7 use case.

Revision Date 01/31/2005

Revision Number: $\quad 0$

\subsection{Case 8}

Description:

Strategy $=\quad$ Thermal+Fast Recycle

Development Phases $=\quad 2-->3-->4$

Energy future $(3$ cases $)=$

- Continuing energy generation ( $0 \%$ growth, market share $21 \%$ to $9 \%$ in 2050 and $4 \%$ in 2100)

- Continuing nuclear market share (1.8\% growth, $21 \%$ constant market share)

- Growing Market Share Generation (3.2\% growth, market share of electricity increases, $\mathrm{H} 2$ produced)

Exit approaches=

At all times, estimate the ramifications of separations phase-out, i.e., a return to once-through.

Separation $=\quad$ UREX + , then pyro

Transmutation $=$ LWR, VHTR, then FR

$\mathrm{U}=\quad$ Retrievable storage, then "FR"

$\mathrm{Pu}=\quad \mathrm{Pu}+\mathrm{Np} \mathrm{IMF}$

$\mathrm{Np}=\quad \mathrm{Pu}+\mathrm{Np} \mathrm{IMF}$

$\mathrm{Am}=\quad$ Storage, then "FR"

$\mathrm{Cm}=\quad$ Storage, then "FR"

$\mathrm{Cs}+\mathrm{Sr}=\quad$ Long-term storage, then LLW

$\mathrm{Tc}+\mathrm{I}=\quad \mathrm{HLW}$

Priority: $\quad$ Required/FY06

Lanthanides $=$ HLW 
Acceptance Criteria: Able to run Case 8 use case.

Revision Date 01/31/2005

Revision Number: $\quad 0$

\section{Software Quality}

The model identified in this SRS has been evaluated in accordance with the Software Management procedures of the INEEL (MCP-550). Based on that evaluation the VISION is classified as a "Level D" or "Deferrable" software application. The application does not meet the criteria specified for a higher classification level. Data in the deferrable class, if lost, can affect individual performance, but would not affect INEEL mission success. Applications in this class have no requirement to be back online within a specified period of time.

\section{Quality Documentation}

Software classified at a level D requires a minimal Software Management Plan (SMP) be completed. The following document will be prepared for this model:

A. Software Management Plan (SMP), which will include:

- Software quality assurance plan (SQAP)

- Software configuration management plan (SCMP)

B. Software requirements specification (SRS)

C. User documentation

Optional software application documentation that may be completed includes:

A. Requirements traceability matrix (RTM)

B. Design description for software (DDS)

C. Software test plan (STP; includes test cases and test report)

\section{Performance Testing}

Performance testing will be in accordance with the software quality assurance plan and the software test plan. Presentations and publications for external communication using data or results from VISION will require peer review before submittal.

\section{Anticipated Future Improvements}

The following are potential elements that are not currently included in this set of requirements for the model, but are anticipated to be desirable in future versions of the model once the original set of requirements are satisfied.

- Groundwater dose index of SNF - Similar to radiotoxicity except radiotoxicity only addresses the dose conversion factors of each isotope ( $\mathrm{Sv} / \mathrm{Bq} \times \mathrm{Bq}$-inventory summed over isotopes). Groundwater dose also includes consideration of transport and dilution in the environment ( $\mathrm{Sv} / \mathrm{Bq}$ dose conversion factor $\mathrm{x} \mathrm{Bq}-$ consumed/Bq-inventory $\mathrm{x}$ Bq-inventory summed over isotopes)

- Weapons usable (WU) inventory = kg-weapons-usable isotope/kg-critical-massisotope, summed over isotopes 
- Heat generation, $\mathrm{W} / \mathrm{kg}$

- Gamma field, $\mathrm{Gy} / \mathrm{kg}$ ( $\mathrm{Sv}=$ =sievert, Gy=gray)

- Neutron field, $\mathrm{n} / \mathrm{kg}$-second or Gy/kg

- Alpha field

- Power produced by reactors

- Average age of reactors in service

\section{Reference Documents}

Shropshire, D.E., K.A. Williams, W.B. Boore, J.D. Smith, B.W. Dixon, M. DunzikGougar, R.D. Adams. 2004. 2004 Advanced Fuel Cycle Cost Basis. Idaho National Engineering and Environmental Laboratory, Idaho Falls, Idaho 83415. INEEL/EXT-0402282 Draft. 